\title{
Activation of AMPK inhibits PDGF-induced pulmonary arterial smooth muscle cells proliferation and its potential mechanisms
}

\author{
Yang Song ${ }^{1 *}$, Yuanyuan $\mathrm{Wu}^{1 *}$, Xiaofan $\mathrm{Su}^{1}$, Yanting $\mathrm{Zhu}{ }^{1}$, Lu Liu ${ }^{1}$, Yilin $\mathrm{Pan}^{1}$, \\ Bo Zhu ${ }^{1}$, Lan Yang ${ }^{1}$, $\mathrm{Li} \mathrm{Gao}^{2}$, Manxiang $\mathrm{Li}^{1}$
}

${ }^{1}$ Department of Respiratory and Critical Care Medicine, the First Affiliated Hospital of Medical College, Xi'an Jiaotong University, Xi'an, Shaanxi, PR China, 710061

${ }^{2}$ Division of Allergy and Clinical Immunology, Department of Medicine, The Johns Hopkins University School of Medicine, Baltimore MD USA, 21224

* These two authors contributed equally to this work

\section{Address correspondence to:}

Dr. Manxiang Li

Department of Respiratory Medicine, the First Affiliated Hospital of Medical College, Xi'an Jiao Tong University

No. 277, West Yanta Road,

Xi'an, Shaanxi, P.R. China 710061

Telephone: +86-029-85323219

E-mail address: manxiangli@ hotmail.com 


\section{Abstract}

The aims of the present study were to examine signaling mechanisms for PDGF-induced pulmonary arterial smooth muscle cells (PASMC) proliferation and to determine the effect of AMPK activation on PDGF-induced PASMC proliferation and its underlying mechanisms. PDGF activated PI3K/Akt/mTOR signaling pathway, and this in turn up-regulated Skp2 and consequently reduced p27 leading to PASMC proliferation. Prior incubation of PASMC with metformin induced a dramatic AMPK activation and significantly blocked PDGF-induced cell proliferation. PASMC lacking AMPK $\alpha 2$ were resistant to the inhibitory effect of metformin on PDGF-induced cell proliferation. Metformin did not affect Akt activation but blocked mTOR phosphorylation in response to PDGF; these were accompanied by the reversion of Skp2 up-regulation and p27 reduction. Our study suggests that the activation of AMPK negatively regulates mTOR activity to suppress PASMC proliferation and therefore has a potential value in the prevention and treatment of pulmonary hypertension by negatively modulating pulmonary vascular remodeling.

Key words: Pulmonary arterial smooth muscle cells; AMPK; mTOR; p27; Skp2 


\section{Introduction}

Pulmonary hypertension $(\mathrm{PH})$ is defined as a sustained increase in mean pulmonary arterial pressure of $>25 \mathrm{mmHg}$, measured using right heart catheterization (1). $\mathrm{PH}$ is divided into five groups based on its causes: pulmonary arterial hypertension (PAH); and PH caused by left heart disease, lung diseases and/or hypoxia, chronic pulmonary thromboembolism or unclear multifactorial mechanisms (2). It has been reported that the prevalence of PAH vary from 5 to 52 cases/million population, and $\mathrm{PH}$ is present in up to $70 \%$ of those with severe left ventricular systolic/diastolic dysfunction (3). PH may affect up to $50 \%$ of patient populations with chronic obstructive pulmonary disease (3). The prevalence of chronic thromboembolic PH ranges from $0.5 \%$ to $3.8 \%$ in those with acute pulmonary embolism (3). All types of PH have very similar pathogenesises, including persistent pulmonary vasoconstriction and vascular remodeling and thrombosis in situ $(1,4)$. Vascular remodeling is extremely critical in the development of $\mathrm{PH}$, which is majorly caused by pulmonary arterial smooth muscle cells (PASMC) proliferation/migration and over-deposition of extracellular matrix (1). Therefore, exploring the molecular mechanisms responsible for PASMC proliferation and searching for new targets are critical for the prevention and treatment of $\mathrm{PH}$.

AMPK has been shown to be a cellular metabolic sensor with serine/threonine kinase activity, which is activated by cellular depletion of ATP or several chemicals independent of energy crisis (5-8). Activation of AMPK regulates a wide variety of 
pathophysiological processes such as substrate metabolism, protein synthesis, cell proliferation, and apoptosis (9). Studies have shown that the activation of AMPK inhibits proliferation of a variety of tumor cells as well as non-malignant cells (10-12). It has been shown that the activation of AMPK suppresses airway smooth muscle cells proliferation induced by PDGF and serotonin (13-14). Recent studies in animal model of PH have demonstrated that the activation of AMPK attenuates the development of PH by negatively regulating vascular remodeling (15-16). Yet, the molecular mechanisms underlying AMPK-induced suppression of pulmonary artery remodeling, particularly PASMC proliferation, are not fully defined.

Growth factor PDGF has been demonstrated to be involved in the development of PH by stimulating PASMC proliferation (17). The activation of PI3K/Akt/mTOR cascade has been shown to mediate PDGF stimulation of cell proliferation in a variety of cell types including PASMC (18-19). However, the down-stream targets of this pathway associated with cell proliferation are still largely unclear, and the molecular mechanisms underlying AMPK suppression of PASMC proliferation are also unknown. To address these issues, the activation of PI3K/Akt/mTOR pathway and cell proliferation were assessed in primary cultured PASMC stimulated with PDGF, and the levels of Skp2 and p27 protein were also examined. The effect of AMPK activation on PDGF-induced PASMC proliferation was determined and its mechanisms were further explored. 


\section{Materials and methods}

\subsection{Cell preparation and culture}

Primary cultured PASMC were isolated from pulmonary arteries of Sprague-Dawley rats weighted from 70 to $80 \mathrm{~g}$ by the methods described previously (20). All animal care and experiments were performed in accordance with the Guide for the Care and Use of Laboratory Animals of Xi'an Jiaotong University Animal Experiment Center. All protocols used in this study were approved by the Laboratory Animal Care Committee of Xi' an Jiaotong University. Briefly, the pulmonary arteries were rapidly removed from euthanized rats by $\mathrm{CO}_{2}$ overdose, washed in phosphate-buffered saline $\left(4^{\circ} \mathrm{C}\right)$, and then dipped into Dulbecco's Modified Eagle Medium (DMEM, Gibco) with 10\% fetal bovine serum (FBS, Sijiqing, Hangzhou, China), $100 \mathrm{U} / \mathrm{ml}$ penicillin, and $100 \mu \mathrm{g} / \mathrm{ml}$ streptomycin (complete DMEM). A thin layer of the adventitia was carefully stripped off with a forceps and the endothelium was removed by gently scratching the intima surface with an elbow tweezers. Next, the arteries were cut into 1-mm pieces and placed into a culture flask and incubated at $37^{\circ} \mathrm{C}$ in an atmosphere of $95 \%$ air and $5 \% \mathrm{CO}_{2}$ till cells reaching $80 \%$ confluence. The purity and identity of PASMC were determined by their typical morphological pattern and by immunofluorescence staining with specific antibody against $\alpha$-actin. All experiments were performed using cells between passages 4 and 8 . Before each experiment, cells were incubated in 1\% FBS-DMEM overnight to minimize serum-induced effects on the cells. PDGF (Peprotech, distillated water as vehicle) was used to stimulate cell proliferation. Ly294002 (Sigma, DMSO as vehicle) was applied 
to inhibit PI3K activity. Rapamycin (Cell Signaling Technology, DMSO as vehicle) was used as an mTOR inhibitor. Metformin was purchase from Bristol-Myers Squibb biopharmaceutical company (DMEM as vehicle).

\section{2. siRNA transfection}

To silence the expression of Skp2 or AMPK $\alpha 2$ protein, PASMC were transfected with 100 nM sequence-specific (GenePharma Co.,Ltd, Shanghai, China) or non-targeting siRNA (GenePharma Co.,Ltd, Shanghai, China) using Lipofectamine ${ }^{\mathrm{TM}} 2000$ reagent (Invitrogen). Brifely, PASMC were cultured until they reached 30-50\% confluence. siRNA and Lipofectamine were diluted in serum-free DMEM, and incubated for 5 minutes at room temperature. siRNA was mixed with Lipofectamine and incubated at room temperature for 20 minutes. Then, the complex of siRNA and Lipofectamine was added into cells and cells were cultured for 48 hours at $37^{\circ} \mathrm{C}, 5 \% \mathrm{CO}_{2}$ in a humidified incubator. Effect of siRNA transfection was determined using western blotting.

\subsection{BrdU incorporation assay}

To examine PASMC proliferation, the rate of BrdU incorporation was determined using BrdU ELISA Kit (Maibio, Shanghai, China) according to the manufacturer's instructions. Briefly, cells were seeded into 96 -well plate at a density of $5 \times 10^{3}$ cells /well, allowing to adhere for at least 24 hours, and serum starved overnight (1\% FBS in DMEM) before the start of experiments. Cells were treated with PDGF or vehicle for 24 hours, metformin was added 6 hours before PDGF stimulation. Then, BrdU labeling reagent was added to the wells and incubated for 2 hours at $37^{\circ} \mathrm{C}$. Next, cells 
were denatured with FixDenat solution for 30 minutes at room temperature, and followed by incubating with anti-BrdU mAbs conjugated to peroxidase for 90 minutes at room temperature. After removing antibody conjugate, substrate solution was added for reaction of 10 minutes. The absorbance at $370 \mathrm{~nm}$ was determined with a microplate reader (Bio-Rad). The blank corresponded to $100 \mu$ of culture medium with or without BrdU.

\subsection{Immunoblotting}

Cells were lysed in RIPA Lysis Buffer (50mM Tris PH 7.4, 150mM NaCl, $1 \%$ NP40, $0.5 \%$ Sodium deoxycholate, $0.1 \%$ SDS, $1 \mathrm{mM}$ EDTA, $1 \mathrm{mM}$ phenylmethylsulfonyl fluoride, $1 \mathrm{mM} \mathrm{Na}_{3} \mathrm{VO}_{4}, 1 \mathrm{mM} \mathrm{NaF}$, and proteinase inhibitors). Lysates were centrifuged at $13,000 \mathrm{rpm}$ at $4{ }^{\circ} \mathrm{C}$ for 15 minutes, and supernatant was collected as total protein. Protein was separated on a SDS-PAGE gel and transferred to a Trans-Blot Nitrocellulose membrane (Bio-Rad). Polyclonal antibodies against

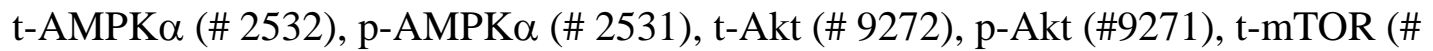
2972), p-mTOR (\# 2971), Skp2 (\# 4313) (Cell Signaling Technology), t-AMPKa2 (\# MBS125164, MyBioSource, Inc.) and monoclonal antibodies against glyceraldehyde-3-phosphate dehydrogenase (GAPDH, \# 2118), p27 (\# 3688) (Cell Signaling Technology) were used following manufacturer's protocols.

Peroxidase-conjugated goat anti-rabbit IgG was used as the secondary antibody (Sigma \# A0545). Reactions were developed with SuperSignal West Pico Chemiluminescent Substrate (Pierce Inc) and exposure to autoradiographic film. Signaling was quantified from scanned films using Quality One software (Bio-Rad). 


\subsection{Statistical analysis}

Values are presented as mean \pm S.D. Data were analyzed using one-way ANOVA followed by a post-hoc Student's t-test. $\mathrm{p}<0.05$ was considered to represent significant difference between groups.

\section{Results}

3.1. PDGF stimulates PASMC proliferation by activating PI3K/Akt/mTOR signaling pathway

To examine the effect of PDGF on PASMC proliferation, cells were incubated with different concentrations of PDGF ranging from 0 to $30 \mathrm{ng} / \mathrm{ml}$ for 24 hours and cell proliferation was determined by BrdU incorporation assay. As shown in Figure 1A, PDGF dose-dependently stimulated PASMC proliferation, and $10 \mathrm{ng} / \mathrm{ml}$ PDGF triggered a 1.93-fold increase in BrdU incorporation compared to control $(\mathrm{p}<0.01)$, indicating that PDGF effectively stimulates PASMC proliferation.

To further explore the mechanisms underlying PDGF-induced PASMC proliferation, phosphorylation levels of Akt and mTOR were determined using western blotting. 10ng/ml PDGF induced a 1.89-fold increase in Akt phosphorylation (Figure 1B) and a 1.76-fold increase in mTOR phosphorylation (Figure 1C) compared to control (both $\mathrm{p}<0.05$ versus control). To investigate whether activation of PI3K/Akt/mTOR signaling pathway particularly mediated PDGF-stimulated PASMC proliferation, cells were pretreated with either $25 \mu \mathrm{M}$ Ly294002 (a selective PI3K inhibitor) or 100nM 
rapamycin (a macrolide antibiotic that selectively inhibits the activity of mTOR) for 30 minutes before stimulation with PDGF (10ng/ml). Figure 1D demonstrates that Ly294002 and rapamycin dramatically suppressed PDGF-induced PASMC

proliferation, and BrdU incorporation rate reduced from a 1.85-fold increase to a 1.09 and a 1.12-fold increase over control, respectively (both $p<0.01$ versus PDGF-stimulated cells). These results suggest that activation of PI3K/Akt/mTOR specifically mediates PDGF stimulation of PASMC proliferation.

\subsection{Up-regulation of $S k p 2$ and reduction of p27 by PI3K/Akt/mTOR pathway} mediates PDGF-induced PASMC proliferation

It has been shown that elevation of S phase kinase-associated protein 2 (Skp2) is required for the ubiquitinylation of p27 and its consequent degradation that is associated with cell cycle progression and proliferation in several types of cell (21-23). To examine whether similar changes in Skp2 and p27 are coupled to the PI3K/Akt/mTOR pathway and mediate PDGF-induced PASMC proliferation, cells were stimulated with $10 \mathrm{ng} / \mathrm{ml}$ PDGF for 24 hours with or without pretreatment with either $25 \mu \mathrm{M}$ Ly294002 or 100nM rapamycin for 30 minutes, and the protein levels of Skp2 and p27 were determined. PDGF stimulation resulted in a 1.73-fold increase in Skp2 protein level compared to control (Figure 2A, $\mathrm{p}<0.05$ ), while the presence of either Ly294002 or rapamycin reduced PDGF-induced Skp2 protein level to a 1.10 and a 1.09-fold increase over control, respectively (Figure 2A, both $\mathrm{p}<0.05$ versus PDGF-treated cells). Figure 2B indicates that PDGF dramatically reduced p27 protein level, which declined to 0.32 -fold over control $(\mathrm{p}<0.05)$, while pre-incubation of cells 
with either Ly294002 or rapamycin increased p27 protein level to 0.84-fold and 0.81-fold over control, respectively, in PDGF-stimulated cells (both $\mathrm{p}<0.05$ versus PDGF-treated cells). These results suggest that the activation of PI3K/Akt/mTOR signaling pathway modulates Skp2 and p27 protein expression.

To determine whether up-regulation of Skp2 by PI3K/Akt/mTOR cascade specifically mediated p27 reduction and PASMC proliferation in response to PDGF, Skp2 was first silenced with sequence specific siRNA and then p27 protein level and cell proliferation were measured in the presence of PDGF. As shown in Figure 3A, transfection of PASMC with sequence specific Skp2 siRNA for 48 hours significantly reduced Skp2 protein level to $25 \%$ of control ( $\mathrm{p}<0.01$ versus control cells), whereas non-targeting siRNA did not change the Skp2 protein level. Loss of Skp2 by siRNA silencing reversed PDGF-induced p27 reduction (Figure 3B; $<<0.05$ versus PDGF-stimulated cells) and cell proliferation (Figure 3C; $p<0.05$ versus PDGF-stimulated cells), non-targeting siRNA did not affect p27 protein level and cell proliferation. These results suggest that Skp2 lies down-stream of PI3K/Akt/mTOR signaling and particularly reduces p27 protein level leading to PASMC proliferation.

\subsection{Activation of AMPK by metformin inhibits PDGF-stimulated PASMC}

proliferation

PASMC were pre-treated with metformin $(10 \mathrm{mM})$ for 6 hours, and followed by 10 ng/ml PDGF stimulation for 24 hours, and then cell proliferation was assessed with BrdU incorporation assay. Figure 4A shows that metformin dramatically suppressed 
PDGF-induced PASMC proliferation, BrdU incorporation rate dropped from a 2.00-fold increase over control in PDGF-stimulated cells to a 1.20-fold increase over control in metformin and PDGF-treated cells $(\mathrm{p}<0.05)$. Figure 4B demonstrates that $10 \mathrm{mM}$ metformin induced a 2.21-fold increase in AMPK phosphorylation over control $(\mathrm{p}<0.01)$.

To determine whether the activation of AMPK is responsible for the inhibitory effect of metformin on PASMC proliferation, AMPK $\alpha 2$ knockdown was carried out in the study. Transfection of AMPK $\alpha 2$-specific siRNA for 48 hours reduced the AMPK $\alpha 2$ protein level to $29.21 \%$ of control in PASMC (Figure $5 \mathrm{~A}, \mathrm{p}<0.01$ versus control cells), whereas non-targeting siRNA did not change the AMPK $\alpha 2$ level. Transfection of AMPK $\alpha 2$ specific siRNA reversed the effect of metformin on cell proliferation, BrdU incorporation rate was raised from a 1.10-fold increase over control in metformin and PDGF-treated cells to a 2.20-fold increase over control in cells lacking AMPK $\alpha 2$ in the presence of metformin and PDGF (Figure 5B, $p<0.01$ ), while non-targeting siRNA did not affect the effect of metfomin on PDGF-induced cell proliferation. These results suggest that the activation of AMPK mediates the effect of metfomin on PASMC proliferation.

\subsection{Molecular mechanisms underlying AMPK inhibition of PASMC proliferation}

To clarify the mechanisms underlying AMPK suppression of PDGF-induced PASMC proliferation, phosphorylation levels of Akt and mTOR and protein expressions of Skp2 and p27 were determined in cells under different interventions. Treatment of 
cells with metformin did not change PDGF-induced Akt phosphorylation (Figure 6A), but suppressed PDGF-elicited mTOR phosphorylation (Figure 6B), which dropped from a 1.86-fold increase over control in PDGF-stimulated cells to a 0.91-fold increase over control in metformin and PDGF-treated cells $(\mathrm{p}<0.05)$. Knockdown of AMPK $\alpha 2$ reversed the effect of metformin on PDGF-induced mTOR phosphorylation, which increased to 1.51 -fold over control again $(\mathrm{p}<0.05$ versus metformin and PDGF-treated cells), but non-targeting siRNA did not affect mTOR phosphorylation. These results suggest that AMPK acts on mTOR, a down-stream target of Akt.

To examine whether the modulation of mTOR by AMPK regulates the expression of Skp2 and p27 which contribute to the suppression of PASMC proliferation, levels of Skp2 and p27 protein were determined in cells. Figure $6 \mathrm{C}$ shows that metformin reduced PDGF-induced Skp2 protein expression, which declined from a 1.61-fold increase to a 1.11-fold increase over control $(\mathrm{p}<0.05)$, whereas loss of AMPK $\alpha 2$ reversed the inhibitory effect of metformin on Skp2 protein level, which increased to 1.56-fold over control again ( $\mathrm{p}<0.05$ versus metformin and PDGF-treated cells). Figure 6D demonstrates that metformin suppressed PDGF-induced p27 protein reduction, which was raised from 0.40-fold over control in PDGF-treated cells to 1.10 -fold over control in metformin and PDGF-treated cells $(\mathrm{p}<0.05)$. Deletion of AMPK $\alpha 2$ blocked metformin-induced increase in p27 protein level in PDGF-stimulated cells, which declined to 0.55 -fold over control $(\mathrm{p}<0.05$ versus metformin and 
PDGF-treated cells). These results suggest that the activation of AMPK by metformin inhibits PASMC proliferation by modulating mTOR-dependent Skp2 and p27 expression.

\section{Discussion}

In the present study, we have shown that PDGF stimulates PASMC proliferation by activating PI3K/Akt/mTOR signaling pathway, which is coupled to an up-regulation of Skp2 and consequent p27 reduction. The activation of AMPK by metformin inhibits PDGF-induced PASMC proliferation, and the mechanisms are associated with AMPK modulation of mTOR-mediated Skp2 and p27 expression. These results provide important insights into PDGF stimulation of cell proliferation and highlight a novel mechanism whereby activation of AMPK may prevent/treat PH by inhibiting PASMC proliferation and vascular remodeling.

It is well-known that the growth factor PDGF is involved in the pulmonary vascular remodeling and contributes to the development of $\mathrm{PH}$ (24) by PI3K/Akt cascade-mediated PASMC proliferation (25). A study on peripheral arterial smooth muscle cells indicates that PDGF-trigged cell proliferation is associated with the alterations of Skp2 and p27 proteins, which lie down-stream of PI3K/Akt signaling (26). p27 is a cdk-inhibitory protein that plays an important role in the control of cell cycle progression and cell proliferation(20). Reduction of p27 is associated with the proliferation of cancer cells and non-malignant cells (27-29). Studies have shown that 
post-transcriptional regulation is one of the critical mechanisms for determining p27 protein level (30-31). S-phase kinase-associated protein 2 (Skp2), a member of F-box proteins, is a subunit of SCF complex to determine the specificity of the substrate for proteasome degradation (32). SCF-Skp2 mainly ubiquitinates and degrades cyclin-dependent kinase inhibitors (CKIs) such as p27 to promote cell-cycle progression and cell growth (33-34). The present study demonstrated that PDGF-induced PASMC proliferation was also coupled to the up-regulation of Skp2 and consequent $\mathrm{p} 27$ reduction.

mTOR, an evolutionarily conserved serine/threonine protein kinase, integrates with both intracellular and extracellular signals and serves as a central regulator of cell metabolism, growth, proliferation, survival and autophagy (35-36). The activity of mTOR is elevated in many types of human tumors, usually caused by alterations of upstream regulators of mTOR, such as PI3K/Akt activation, loss of PTEN or insufficiency of mTOR-negative regulators (eg, TSC1/2), leading to uncontrolled cell proliferation (36). mTOR promotes specific mRNA translation by activating both the S6K1 and 4E-BP1(22). The inhibition of mTOR has been well shown to inhibit cell proliferation including a wide variety of tumor cells and normal cell types (37). Our study indicated that the suppression of mTOR blocked PDGF-induced PASMC proliferation by down-regulation of Skp2, suggesting that Skp2 is an important down-stream target regulated by mTOR in PASMC. 
Studies have shown that the activation of AMPK suppresses proliferation of a wide variety of cell types $(10,12-13,38)$. Here, we further confirmed that the activation of AMPK also suppressed PASMC proliferation. The results of the current study indicated that AMPK did not affect Akt activation but suppressed mTOR phosphorylation (activation), which blocked PDGF-induced changes of Skp2 and p27, and negatively modulated cell proliferation. Previous study demonstrated that AMPK directly phosphorylates (activates) TSC2, which in turn inhibits mTOR activity (39). AMPK also inhibits mTOR by directly phosphorylating and inactivating Raptor (a component of mTOR complex) in a TSC2-independent manner (40). In addition, AMPK has been shown to phosphorylate p27 at site of threonine 197 resulting in its resistance to proteasomal degradation (41-42). The present study clarifies the major target modulated by AMPK to confer its suppression on cell proliferation induced by PDGF compared with previous studies (13-14).

Metformin belongs to the biguanide class of oral hypoglycemic agents (43) and has been widely used in clinic to treat type II diabetes. Epidemiologic investigations have reported that the usage of metformin is associated with a decreased incidence of many types of cancer in clinical settings (11-12), suggesting that metformin might suppress cancer cell growth in human, and the activation of AMPK and consequent inhibition of mTOR is responsible for this benefaction (44-45). Our present and previous studies demonstrated that the activation of AMPK suppressed multiple stimulus-induced PASMC proliferation, implying that AMPK might be a novel target for the treatment 
of $\mathrm{PH}$, however, this still needs to be verified by clinical trials.

\section{Acknowledgments}

This work was supported by Chinese National Science Foundation (No. 81070045 and No. 81330002).

Conflict of Interest: None declared

\section{Figure legends}

Fig.1. Activation of PI3K/Akt/mTOR pathway mediates PDGF-induced PASMC proliferation. A: PASMC were stimulated with different concentrations of PDGF ranging from 0 to $30 \mathrm{ng} / \mathrm{ml}$ for 24 hours, BrdU incorporation rate was determined by BrdU ELISA assay Kit ( $\mathrm{n}=4$ each group). B: PASMC were stimulated with $10 \mathrm{ng} / \mathrm{ml}$ PDGF for 10 minutes, Akt phosphorylation was examined using western blotting ( $\mathrm{n}=4$ each group). C: PASMC were treated with 10ng/ml PDGF for 10 minutes, mTOR phosphorylation was analyzed by immunoblotting ( $n=4$ each group). D: PASMC were prior treated with Ly294002 $(25 \mu \mathrm{M})$ or rapamycin $(100 \mathrm{nM})$ for 30 minutes before stimulation with PDGF $(10 \mathrm{ng} / \mathrm{ml})$ for 24 hours, the rate of BrdU incorporation was measured ( $\mathrm{n}=4$ each group). $* \mathrm{p}<0.05$ versus control; $* * \mathrm{p}<0.01$ versus control; \# $\mathrm{p}<0.01$ versus PDGF-treated cells.

Fig. 2. PI3K/Akt/mTOR pathway mediates PDGF-induced alterations of Skp2 and 
p27. PASMC were pre-treated with Ly294002 $(25 \mu \mathrm{M})$ or rapamycin $(100 \mathrm{nM})$ for 30 minutes before stimulation with PDGF $(10 \mathrm{ng} / \mathrm{ml})$ for 24 hours. Protein levels of Skp2 (A) and p27 (B) were determined using immunoblotting, GAPDH served as loading control ( $\mathrm{n}=4$ each group). Representative western blot and quantification of bands are shown. ${ }^{*} \mathrm{p}<0.05$ versus control, \# $\mathrm{p}<0.05$ versus PDGF-treated cells.

Fig. 3. Skp2 mediates PDGF-induced p27 reduction. A: PASMC were transfected with sequence-specific Skp2 siRNA or non-targeting siRNA for 48 hours. Skp2 protein level was examined using western blotting ( $\mathrm{n}=4$ each group). B: PASMC were prior transfected with sequence-specific Skp2 siRNA or non-targeting siRNA for 24 hours and then stimulated with PDGF (10 ng/ml) for 24 hours, p27 protein level was determined by western blotting ( $\mathrm{n}=4$ each group). C: PASMC were treated with PDGF (10 ng/ml) for 24 hours with or without prior silencing Skp2 for 24 hours, and then BrdU incorporation rate was measured ( $\mathrm{n}=4$ each group). $* * \mathrm{p}<0.01$ versus control; * $\mathrm{p}<0.05$ versus control; \# $\mathrm{p}<0.05$ versus PDGF-treated cells.

Fig. 4. Activation of AMPK by metformin inhibits PDGF-induced PASMC proliferation. A: PASMC were prior treated with metformin $(10 \mathrm{mM})$ for 6 hours and then stimulated with PDGF (10 ng/ml) for 24 hours, BrdU incorporation rate was measured ( $\mathrm{n}=4$ each group). B: Cells were incubated with metformin $(10 \mathrm{mM})$ for 6 hours, phosphorylation of AMPK was determined using immunoblotting $(n=4$ each group). ${ }^{*} \mathrm{p}<0.01$ versus control; \# $\mathrm{p}<0.05$ versus PDGF-treated cells. 
Fig. 5. AMPK $\alpha 2$ mediates metformin suppression of PASMC proliferation. A:

PASMC were transfected with AMPK $\alpha 2$-specific or non-targeting siRNA for 48 hours, the silencing effect was assessed by western blotting ( $n=4$ each group). B: PASMC were transfected with non-targeting or AMPK $\alpha 2$-specific siRNA for 24 hours, and then treated with $10 \mathrm{mM}$ metformin for 6 hours before stimulation with PDGF (10 ng/ml) for 24 hours, the rate of BrdU incorporation was determined ( $\mathrm{n}=4$ each group). ${ }^{*} \mathrm{p}<0.01$ versus control, $\# \mathrm{p}<0.05$ versus PDGF-treated cells, $\& \mathrm{p}<0.01$ versus metformin and PDGF-treated cells.

Fig.6. Mechanisms underlying AMPK inhibition of PDGF-stimulated PASMC proliferation. A and B: PASMC were prior transfected with AMPK $\alpha 2$-specific or non-targeting siRNA for 48 hours and then treated with $10 \mathrm{mM}$ metformin for 6 hours before stimulation with PDGF (10 ng/ml) for 10 minutes, phosphorylations of Akt (A) and mTOR (B) were examined by western blotting ( $\mathrm{n}=4$ each group). $\mathbf{C}$ and $\mathbf{D}$ : PASMC were prior transfected with AMPK $\alpha 2$-specific or non-targeting siRNA for 24 hours and then treated with $10 \mathrm{mM}$ metformin for 6 hours before stimulation with PDGF (10 ng/ml) for 24 hours. Protein levels of Skp2 (C) and p27 (D) were determined ( $\mathrm{n}=4$ each group). Representative blots and quantification of bands are shown. ${ }^{*} \mathrm{p}<0.05$ versus control; \# $\mathrm{p}<0.05$ versus PDGF-treated cells; \& $\mathrm{p}<0.05$ versus metformin and PDGF-treated cells. 


\section{References}

1. Y. Fukumotoand H. Shimokawa. Recent progress in the management of pulmonary hypertension. Circulation journal: official journal of the Japanese Circulation Society. 75:1801-1810 (2011).

2. S. Rosenkranz. Pulmonary hypertension 2015: current definitions, terminology, and novel treatment options. Clin Res Cardiol. 104:197-207 (2015).

3. G. Strange, D. Playford, S. Stewart, J.A. Deague, H. Nelson, A. Kent, and E. Gabbay. Pulmonary hypertension: prevalence and mortality in the Armadale echocardiography cohort. Heart. 98:1805-1811 (2012).

4. Y. Miura, Y. Fukumoto, K. Sugimura, M. Oikawa, M. Nakano, S. Tatebe, S. Miyamichi, K. Satoh, and H. Shimokawa. Identification of new prognostic factors of pulmonary hypertension. Circulation journal: official journal of the Japanese Circulation Society. 74:1965-1971 (2010).

5. M.H. Zou, X.Y. Hou, C.M. Shi, S. Kirkpatick, F. Liu, M.H. Goldman, and R.A. Cohen. Activation of 5'-AMP-activated kinase is mediated through c-Src and phosphoinositide 3-kinase activity during hypoxia-reoxygenation of bovine aortic endothelial cells. Role of peroxynitrite. J Biol Chem. 278:34003-34010 (2003).

6. Y. Jiang, W. Huang, J. Wang, Z. Xu, J. He, X. Lin, Z. Zhou, and J. Zhang. Metformin plays a dual role in MIN6 pancreatic beta cell function through AMPK-dependent autophagy. Int J Biol Sci. 10:268-277 (2014).

7. W. Zhang, R. Wu, F. Zhang, Y. Xu, B. Liu, Y. Yang, H. Zhou, L. Wang, K. Wan, X. Xiao, and $X$. Zhang. Thiazolidinediones improve hepatic fibrosis in rats with non-alcoholic steatohepatitis by activating the adenosine monophosphate-activated protein kinase signalling pathway. Clin Exp Pharmacol Physiol. 39:1026-1033 (2012).

8. J.K. Zhan, Y.J. Wang, Y. Wang, Z.Y. Tang, P. Tan, W. Huang, and Y.S. Liu. Adiponectin attenuates the osteoblastic differentiation of vascular smooth muscle cells through the AMPK/mTOR pathway. Exp Cell Res. 323:352-358 (2014).

9. A. Peairs, A. Radjavi, S. Davis, L. Li, A. Ahmed, S. Giri, and C. Reilly. Activation of AMPK inhibits inflammation in MRL/lpr mouse mesangial cells. Clinical \& Experimental Immunology. 156:542-551 (2009).

10. H. Motoshima, B.J. Goldstein, M. Igata, and E. Araki. AMPK and cell proliferation-AMPK as a therapeutic target for atherosclerosis and cancer. The Journal of physiology. 574:63-71 (2006).

11. L.A. Cantrell, C. Zhou, A. Mendivil, K.M. Malloy, P.A. Gehrig, and V.L. Bae-Jump. Metformin is a potent inhibitor of endometrial cancer cell proliferation -implications for a novel treatment strategy. Gynecologic oncology. 116:92-98 (2010).

12. I.B. Sahra, Y. Le Marchand-Brustel, J.-F. Tanti, and F. Bost. Metformin in cancer therapy: a new perspective for an old antidiabetic drug? Molecular cancer therapeutics. 9:1092-1099 (2010).

13. A. Ratnovsky, M. Mellema, S.S. An, J.J. Fredberg, and S.A. Shore. Airway smooth muscle proliferation and mechanics: effects of AMP kinase agonists. Mol Cell Biomech. 4:143-157 (2007).

14. P. Zhang, M. Cao, Y. Liu, Z. Lv, Q. Yang, X. Lin, H. Li, and Q. Wan. PDGF-induced airway smooth muscle proliferation is associated with Human antigen $\mathrm{R}$ activation and could be 
weakened by AMPK activation. Mol Biol Rep. 39:5819-5829 (2012).

15. C. Agard, M. Rolli - Derkinderen, E. Dumas - de - La - Roque, M. Rio, C. Sagan, J.

Savineau, G. Loirand, and P. Pacaud. Protective role of the antidiabetic drug metformin against chronic experimental pulmonary hypertension. British journal of pharmacology.

158:1285-1294 (2009).

16. R.-J. Teng, J. Du, A.J. Afolayan, A. Eis, Y. Shi, and G.G. Konduri. AMP kinase activation improves angiogenesis in pulmonary artery endothelial cells with in utero pulmonary hypertension. American Journal of Physiology-Lung Cellular and Molecular Physiology. 304:L29-L42 (2013).

17. Y. Zhao, W. Lv, H. Piao, X. Chu, and H. Wang. Role of platelet-derived growth factor-BB (PDGF-BB) in human pulmonary artery smooth muscle cell proliferation. J Recept Signal Transduct Res. 34:254-260 (2014).

18. X. Zhang, F. Zhang, D. Kong, X. Wu, N. Lian, L. Chen, Y. Lu, and S. Zheng.

Tetramethylpyrazine inhibits angiotensin II-induced activation of hepatic stellate cells associated with interference of platelet-derived growth factor beta receptor pathways. FEBS J. 281:2754-2768 (2014).

19. V.P. Krymskaya, J. Snow, G. Cesarone, I. Khavin, D.A. Goncharov, P.N. Lim, S.C. Veasey, K. Ihida-Stansbury, P.L. Jones, and E.A. Goncharova. mTOR is required for pulmonary arterial vascular smooth muscle cell proliferation under chronic hypoxia. FASEB J. 25:1922-1933 (2011).

20. Y. Wu, L. Liu, Y. Zhang, G. Wang, D. Han, R. Ke, S. Li, W. Feng, and M. Li. Activation of AMPK inhibits pulmonary arterial smooth muscle cells proliferation. Exp Lung Res. 40:251-258 (2014).

21. M. Bondand Y.J. Wu. Proliferation unleashed: the role of Skp2 in vascular smooth muscle cell proliferation. Front Biosci (Landmark Ed). 16:1517-1535 (2011).

22. M.a. Shapira, E. Kakiashvili, T. Rosenberg, and D.D. Hershko. The mTOR inhibitor rapamycin down-regulates the expression of the ubiquitin ligase subunit Skp2 in breast cancer cells. Breast Cancer Research. 8:R46 (2006).

23. M. Pagano. Control of DNA synthesis and mitosis by the Skp2-p27-Cdk1/2 axis. Mol Cell. 14:414-416 (2004).

24. F. Perros, D. Montani, P. Dorfmuller, I. Durand-Gasselin, C. Tcherakian, J. Le Pavec, M. Mazmanian, E. Fadel, S. Mussot, and O. Mercier. Platelet-derived growth factor expression and function in idiopathic pulmonary arterial hypertension. American journal of respiratory and critical care medicine. 178:81-88 (2008).

25. V.P. Krymskaya, J. Snow, G. Cesarone, I. Khavin, D.A. Goncharov, P.N. Lim, S.C. Veasey, K. Ihida-Stansbury, P.L. Jones, and E.A. Goncharova. mTOR is required for pulmonary arterial vascular smooth muscle cell proliferation under chronic hypoxia. The FASEB Journal. 25:1922-1933 (2011).

26. J. Liu, J. Xiu, J. Cao, Q. Gao, D. Ma, and L. Fu. Berberine cooperates with adrenal androgen dehydroepiandrosterone sulfate to attenuate PDGF-induced proliferation of vascular smooth muscle cell A7r5 through Skp2 signaling pathway. Molecular and cellular biochemistry. 355:127-134 (2011).

27. T. Yanagi, J.C. Reed, and S. Matsuzawa. PCTAIRE1 regulates p27 stability, apoptosis and tumor growth in malignant melanoma. Oncoscience. 1:624-633 (2014). 
28. A. Royand S. Banerjee. p27 and leukemia: cell cycle and beyond. J Cell Physiol. 230:504-509 (2015).

29. U.V. Wesley, J.F. Hatcher, and R.J. Dempsey. Sphingomyelin Synthase 1 Regulates Neuro-2a Cell Proliferation and Cell Cycle Progression Through Modulation of p27 Expression and Akt Signaling. Mol Neurobiol. 2:2 (2014).

30. M. Lonjedo, E. Poch, E. Mocholi, M. Hernandez-Sanchez, C. Ivorra, T.F. Franke, R.M. Guasch, and I. Perez-Roger. The Rho family member RhoE interacts with Skp2 and is degraded at the proteasome during cell cycle progression. J Biol Chem. 288:30872-30882 (2013).

31. L. Wu, A.V. Grigoryan, Y. Li, B. Hao, M. Pagano, and T.J. Cardozo. Specific small molecule inhibitors of Skp2-mediated p27 degradation. Chem Biol. 19:1515-1524 (2012).

32. H. Zhang, C. Li, H. Chen, C. Wei, F. Dai, H. Wu, W. Dui, W.M. Deng, and R. Jiao. SCF(Slmb) E3 ligase-mediated degradation of Expanded is inhibited by the Hippo pathway in Drosophila. Cell Res. 25:93-109 (2015).

33. Z. Lu, F. Bauzon, H. Fu, J. Cui, H. Zhao, K. Nakayama, K.I. Nakayama, and L. Zhu. Skp2 suppresses apoptosis in Rb1-deficient tumours by limiting E2F1 activity. Nat Commun. 5:3463 (2014).

34. T. Fujita, W. Liu, H. Doihara, and Y. Wan. Regulation of Skp2-p27 axis by the Cdh1/anaphase-promoting complex pathway in colorectal tumorigenesis. The American journal of pathology. 173:217-228 (2008).

35. E. Dazertand M.N. Hall. mTOR signaling in disease. Current opinion in cell biology. 23:744-755 (2011).

36. Y. Zhaoand Y. Sun. Targeting the mTOR-DEPTOR pathway by CRL E3 ubiquitin ligases: therapeutic application. Neoplasia (New York, NY). 14:360 (2012).

37. A. Ogawa, A.L. Firth, W. Yao, M.M. Madani, K.M. Kerr, W.R. Auger, S.W. Jamieson, P.A. Thistlethwaite, and J.X.-J. Yuan. Inhibition of mTOR attenuates store-operated Ca2+ entry in cells from endarterectomized tissues of patients with chronic thromboembolic pulmonary hypertension. American Journal of Physiology-Lung Cellular and Molecular Physiology. 297:L666 (2009).

38. D.A. Goncharov, T.V. Kudryashova, H. Ziai, K. Ihida-Stansbury, H. DeLisser, V.P. Krymskaya, R.M. Tuder, S.M. Kawut, and E.A. Goncharova. mTORC2 Coordinates Pulmonary Artery Smooth Muscle Cell Metabolism, Proliferation and Survival in Pulmonary Arterial Hypertension. Circulation:CIRCULATIONAHA. 113.004581 (2013).

39. D. Han, S.J. Li, Y.T. Zhu, L. Liu, and M.X. Li. LKB1/AMPK/mTOR signaling pathway in non-small-cell lung cancer. Asian Pac J Cancer Prev. 14:4033-4039 (2013).

40. D.M. Gwinn, D.B. Shackelford, D.F. Egan, M.M. Mihaylova, A. Mery, D.S. Vasquez, B.E. Turk, and R.J. Shaw. AMPK phosphorylation of raptor mediates a metabolic checkpoint. Molecular cell. 30:214-226 (2008).

41. J.D. Short, R. Dere, K.D. Houston, S.L. Cai, J. Kim, J.M. Bergeron, J. Shen, J. Liang, M.T. Bedford, G.B. Mills, and C.L. Walker. AMPK-mediated phosphorylation of murine p27 at T197 promotes binding of 14-3-3 proteins and increases p27 stability. Mol Carcinog. 49:429-439 (2010).

42. M.-H. Zou, X.-Y. Hou, C.-M. Shi, S. Kirkpatick, F. Liu, M.H. Goldman, and R.A. Cohen. Activation of 5' -AMP-activated kinase is mediated through c-Src and phosphoinositide 
3-kinase activity during hypoxia-reoxygenation of bovine aortic endothelial cells Role of peroxynitrite. Journal of Biological Chemistry. 278:34003-34010 (2003).

43. S.C. Liu, Y.K. Tu, M.N. Chien, and K.L. Chien. Effect of antidiabetic agents added to metformin on glycaemic control, hypoglycaemia and weight change in patients with type 2 diabetes: a network meta - analysis. Diabetes, Obesity and Metabolism. 14:810-820 (2012).

44. R.J. Dowling, M. Zakikhani, I.G. Fantus, M. Pollak, and N. Sonenberg. Metformin inhibits mammalian target of rapamycin-dependent translation initiation in breast cancer cells. Cancer research. 67:10804-10812 (2007).

45. W. Shi, D. Xiao, L. Wang, L. Dong, Z. Yan, Z. Shen, S. Chen, Y. Chen, and W. Zhao. Therapeutic metformin/AMPK activation blocked lymphoma cell growth via inhibition of mTOR pathway and induction of autophagy. Cell death \& disease. 3:e275 (2012). 
A

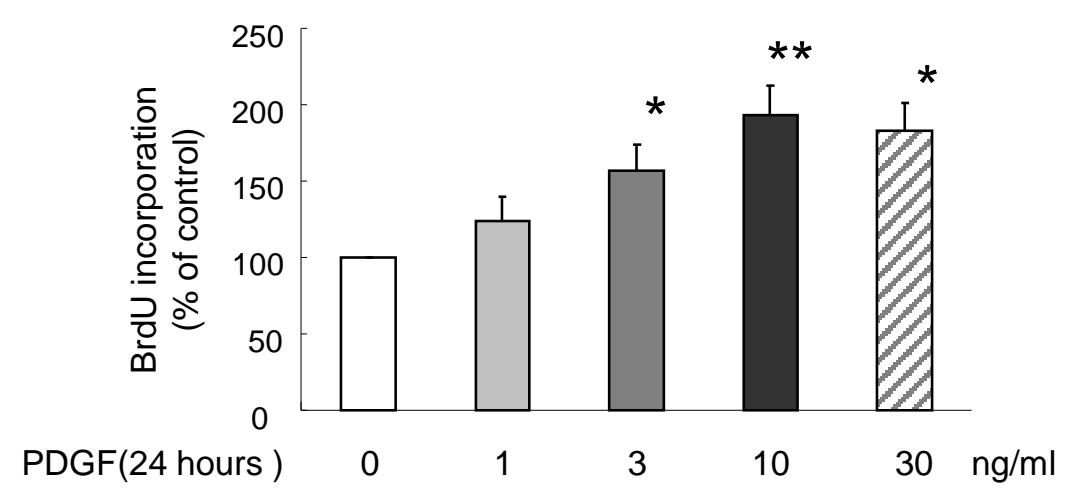

C

Figure 1
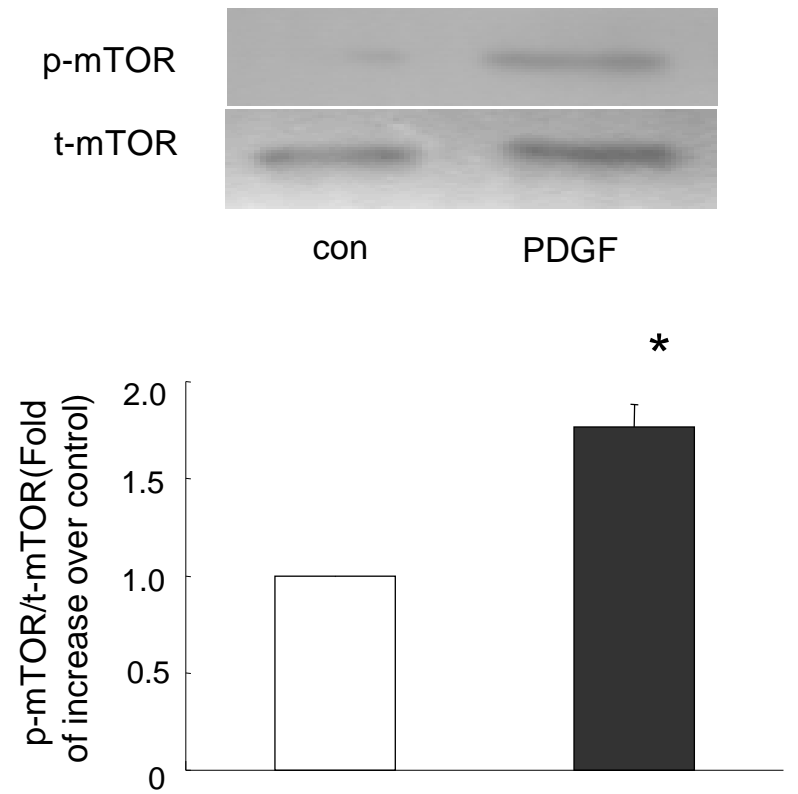

B
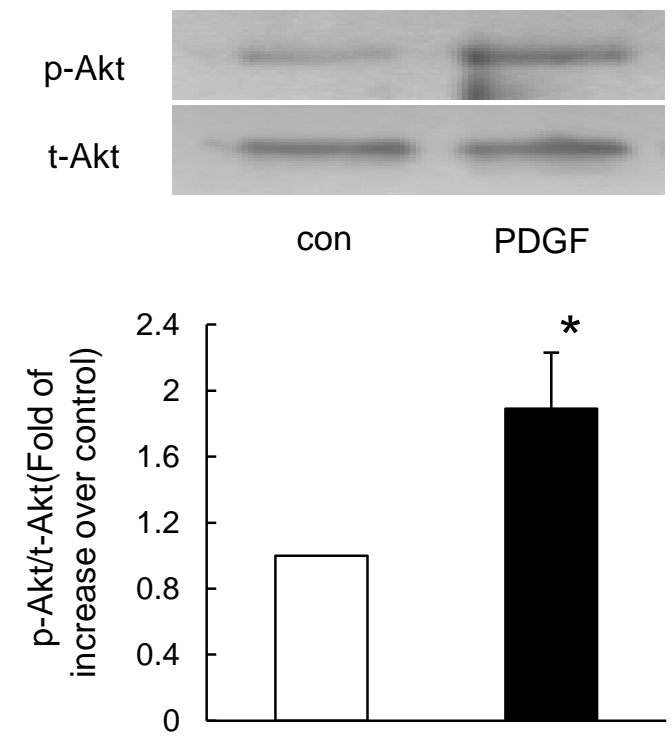

D

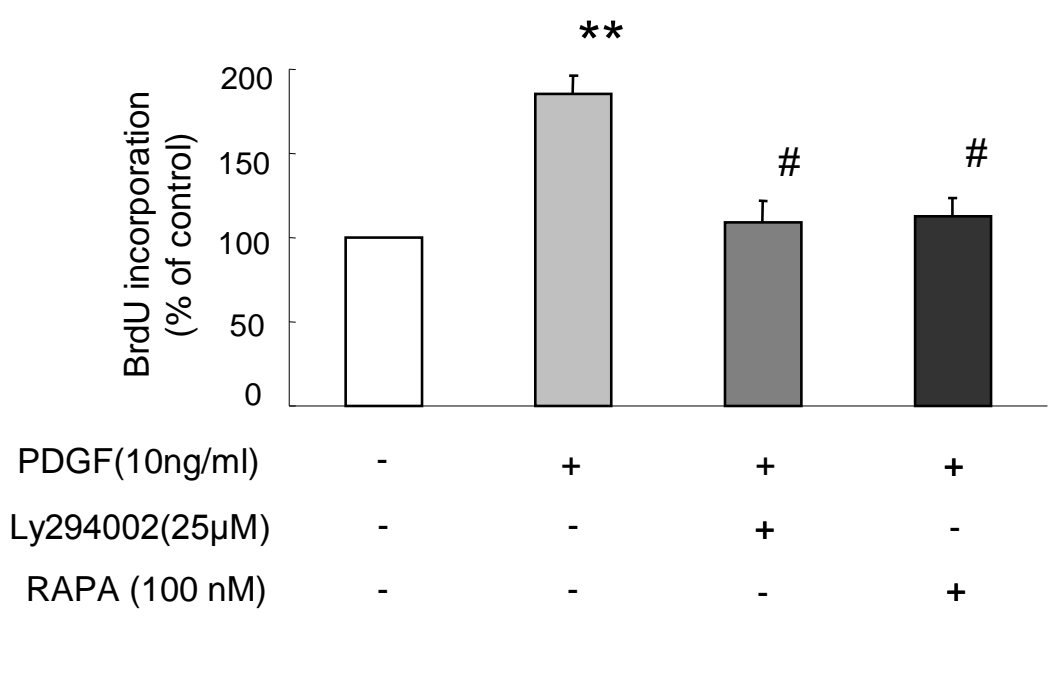


A

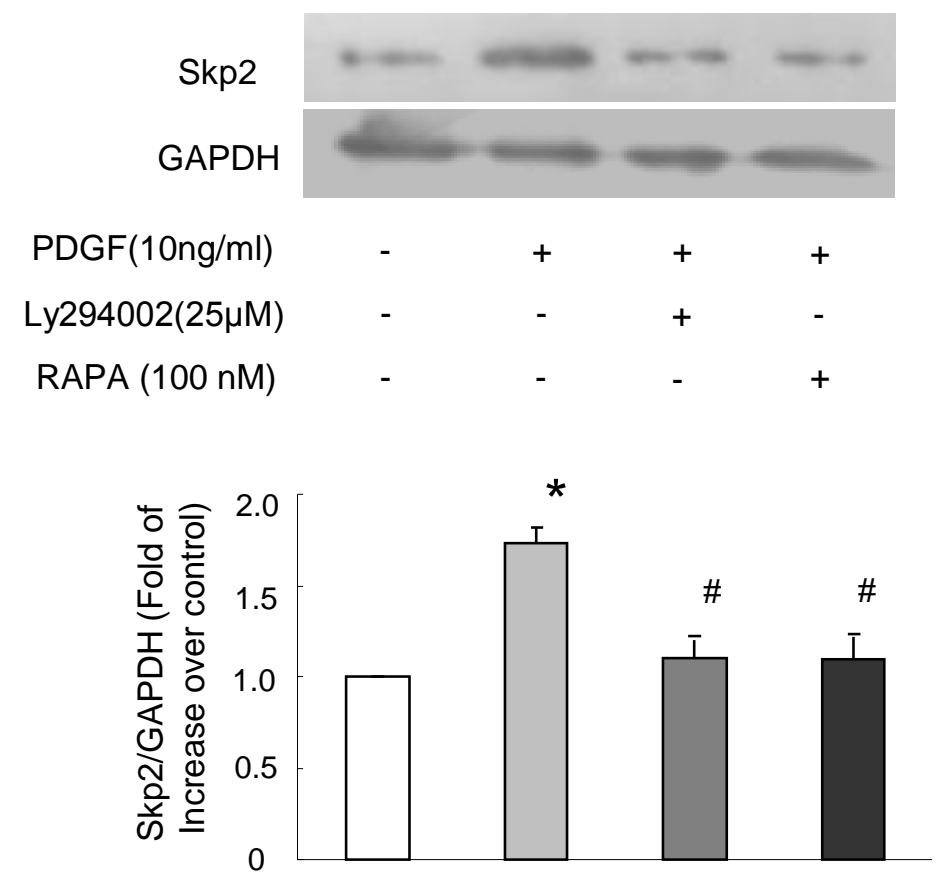

B

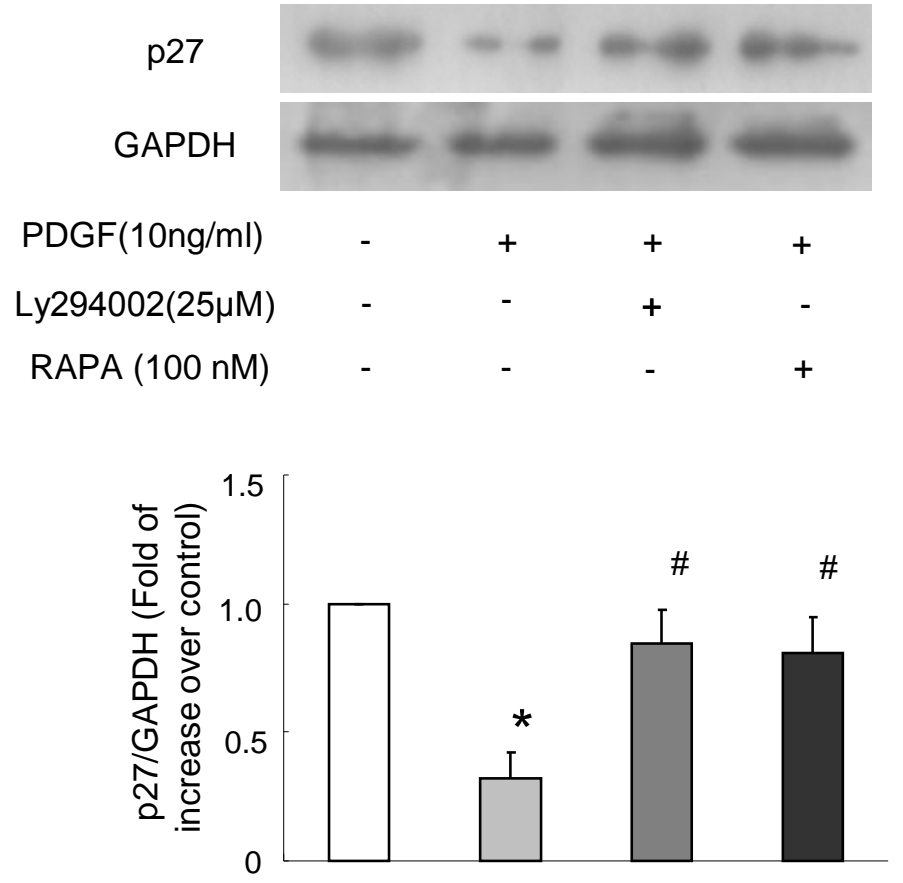

Figure 2 
A

\section{Skp2 \\ GAPDH}

control siRNA

Skp2 siRNA

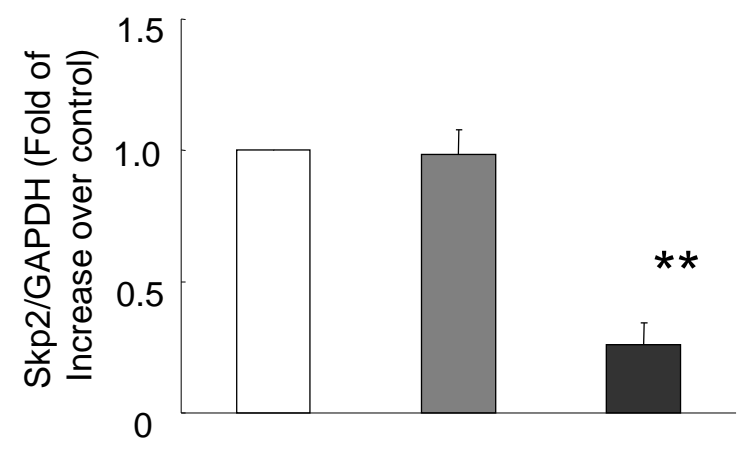

B
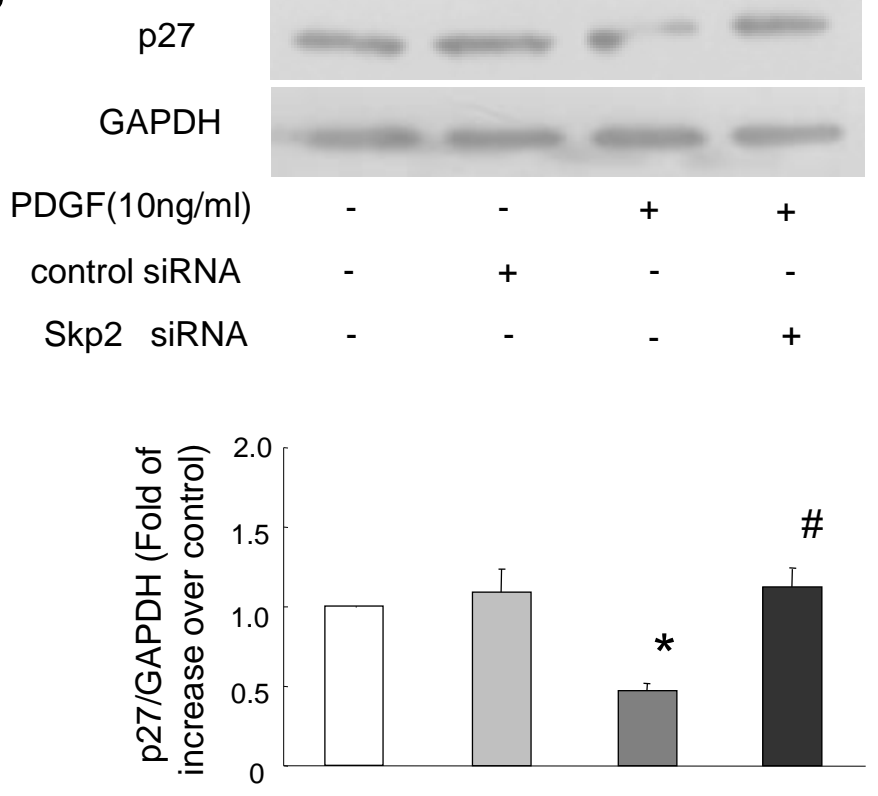

Figure 3

C

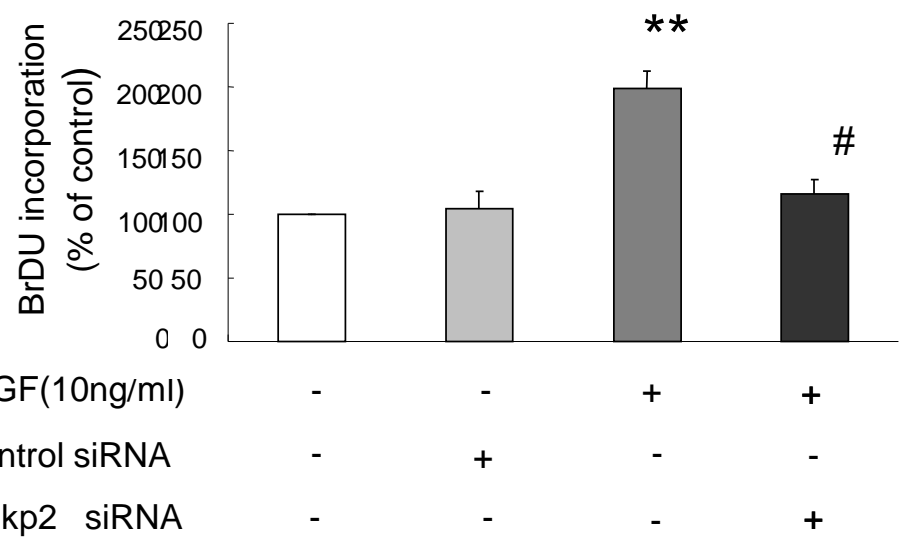


A

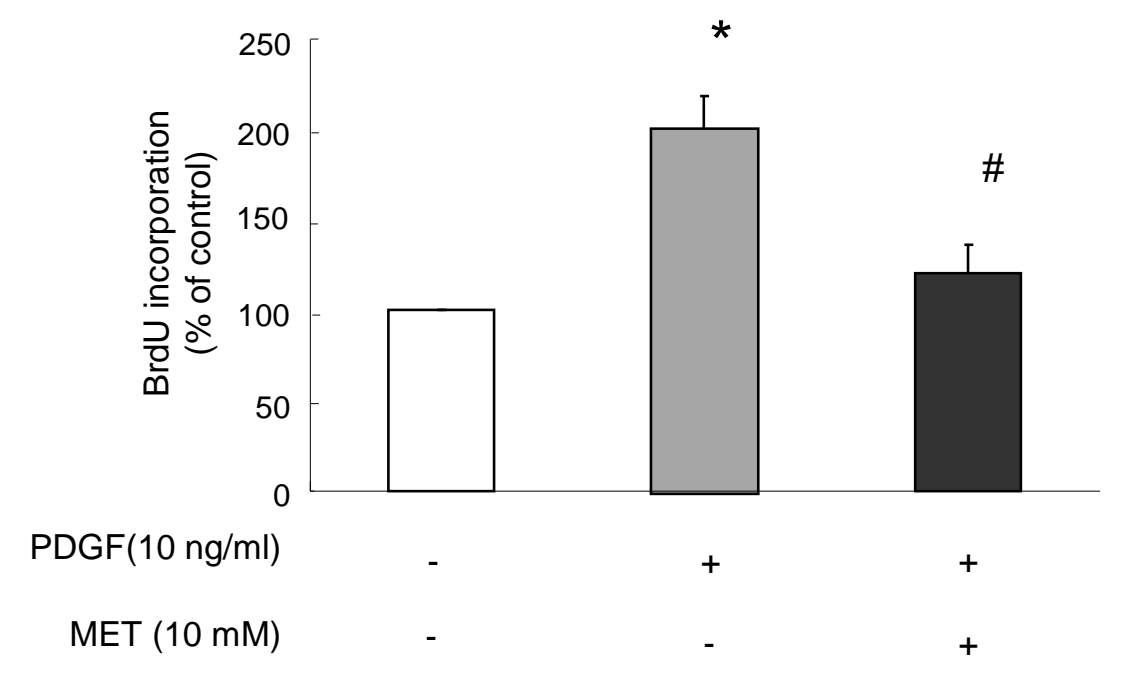

B

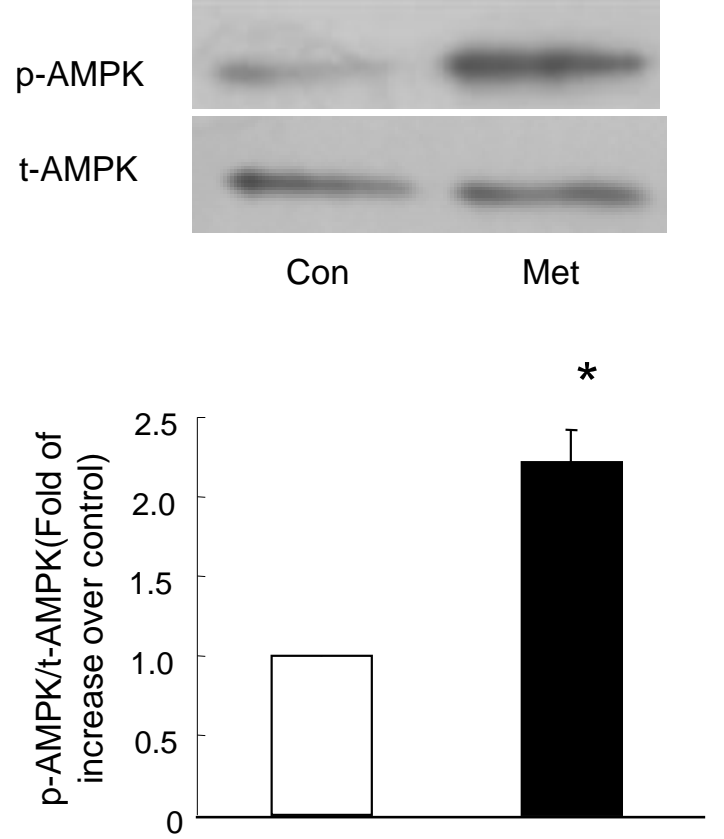

Figure 4 
A

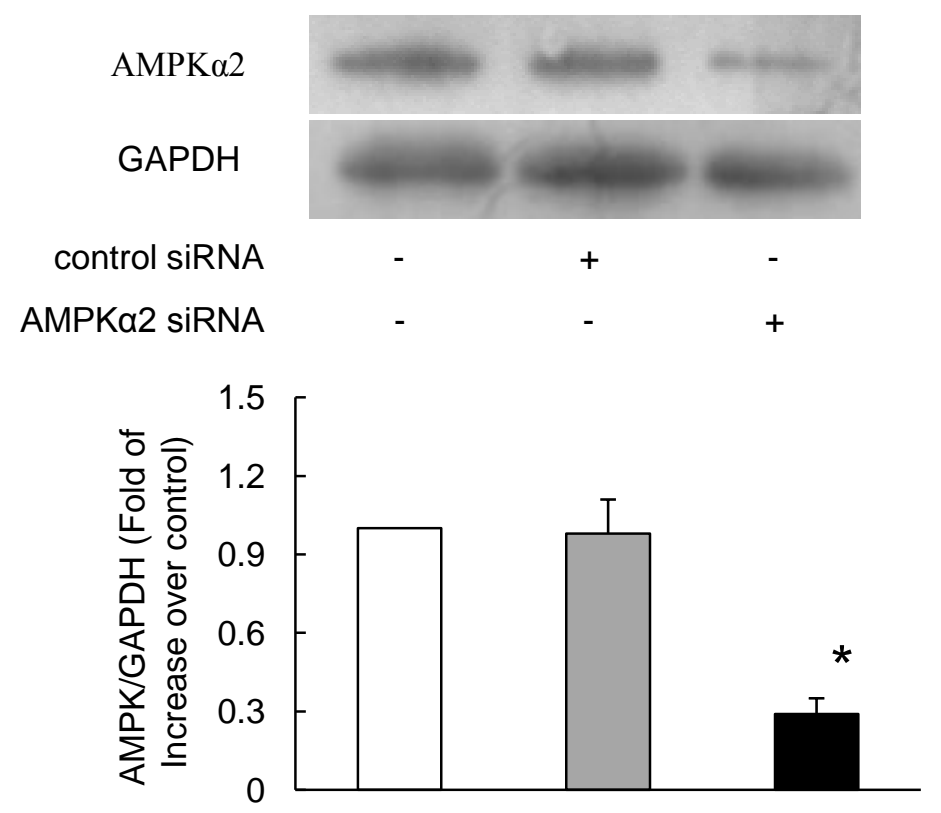

B

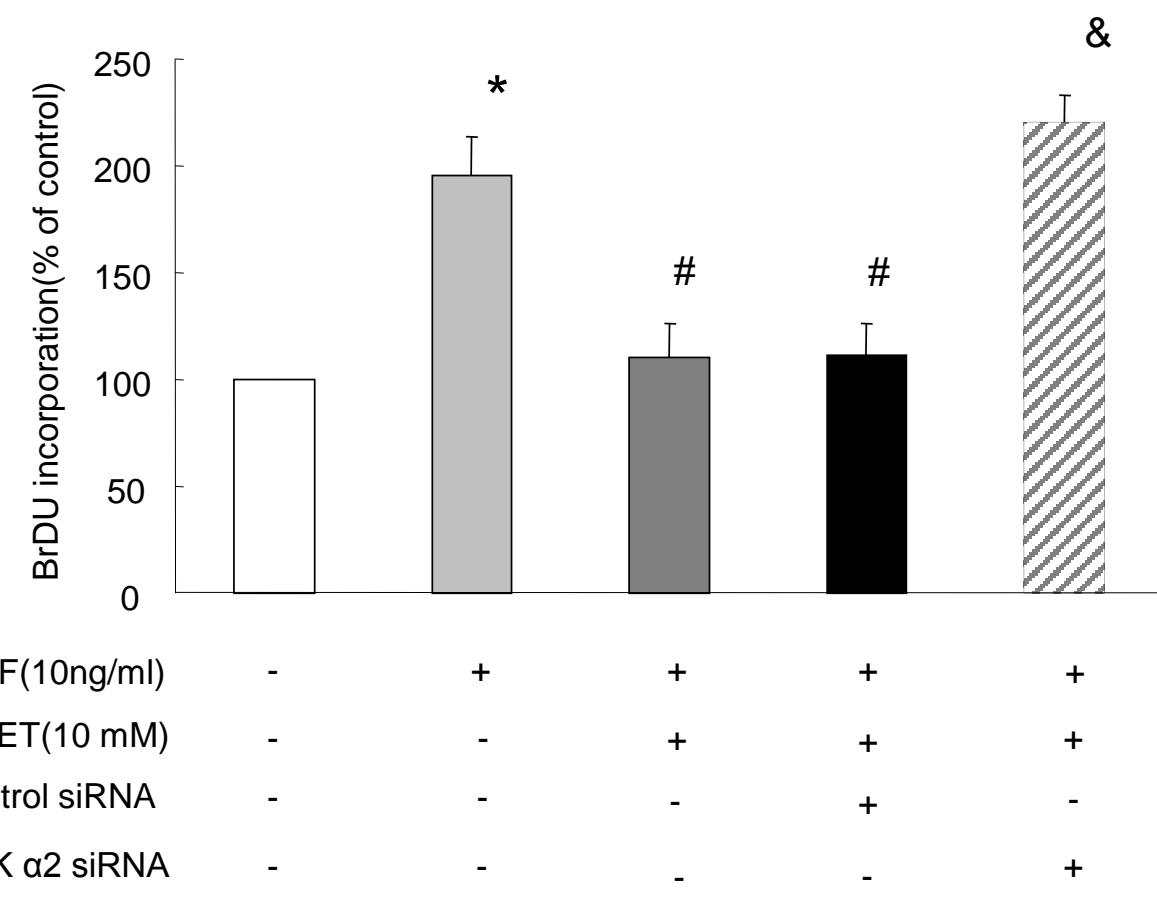

Figure 5 

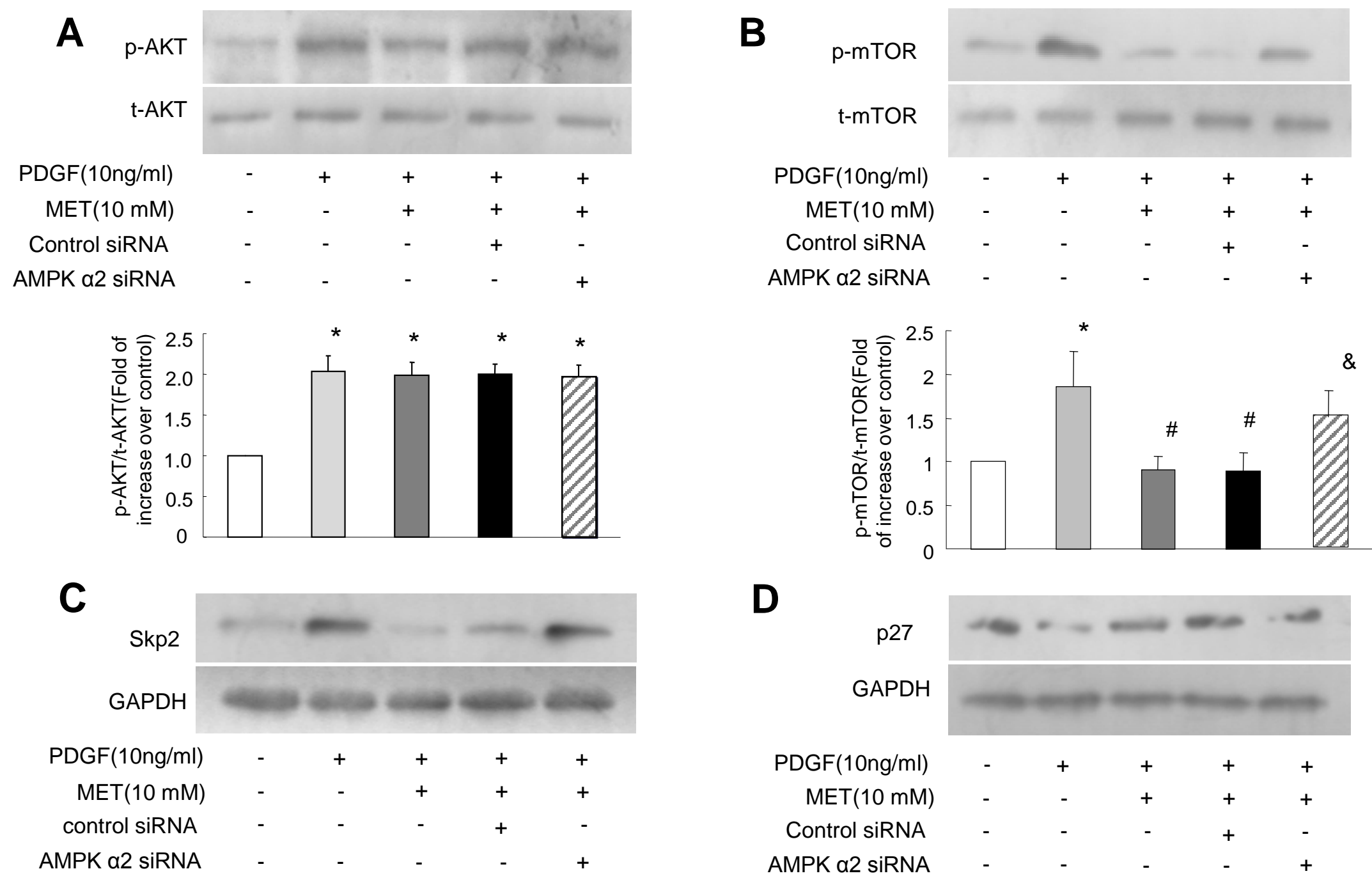

D
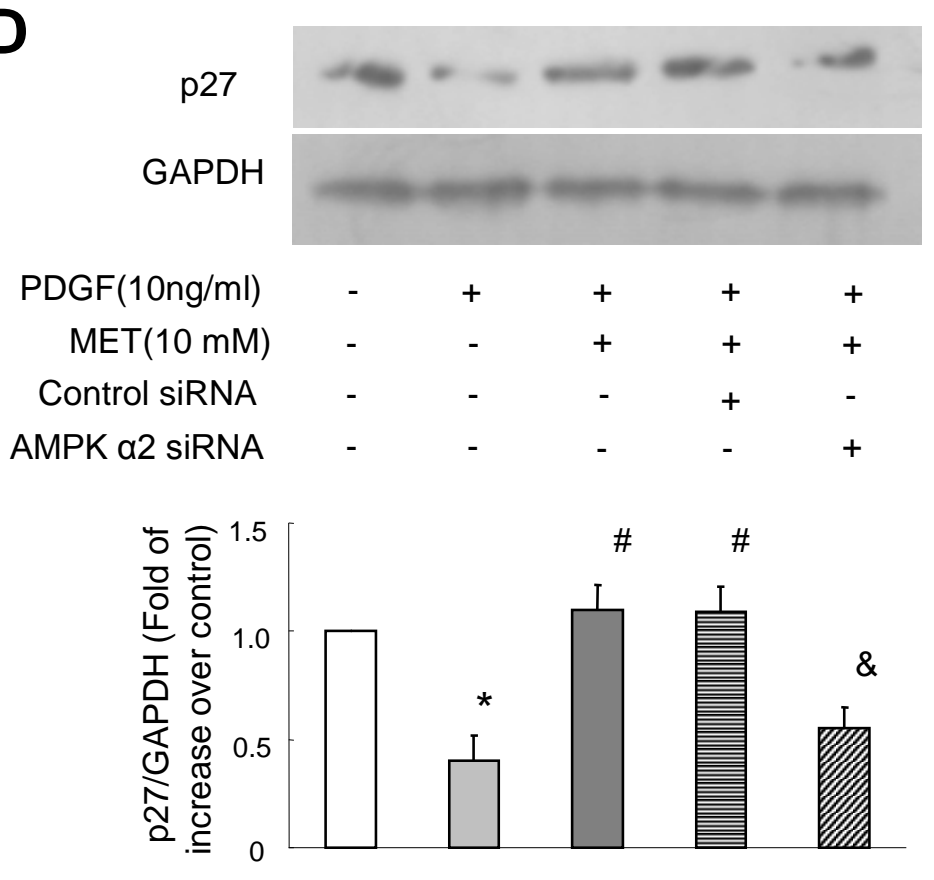

Figure 6

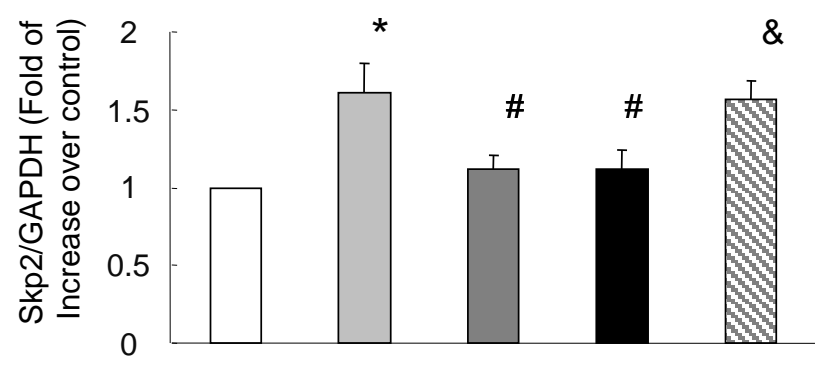




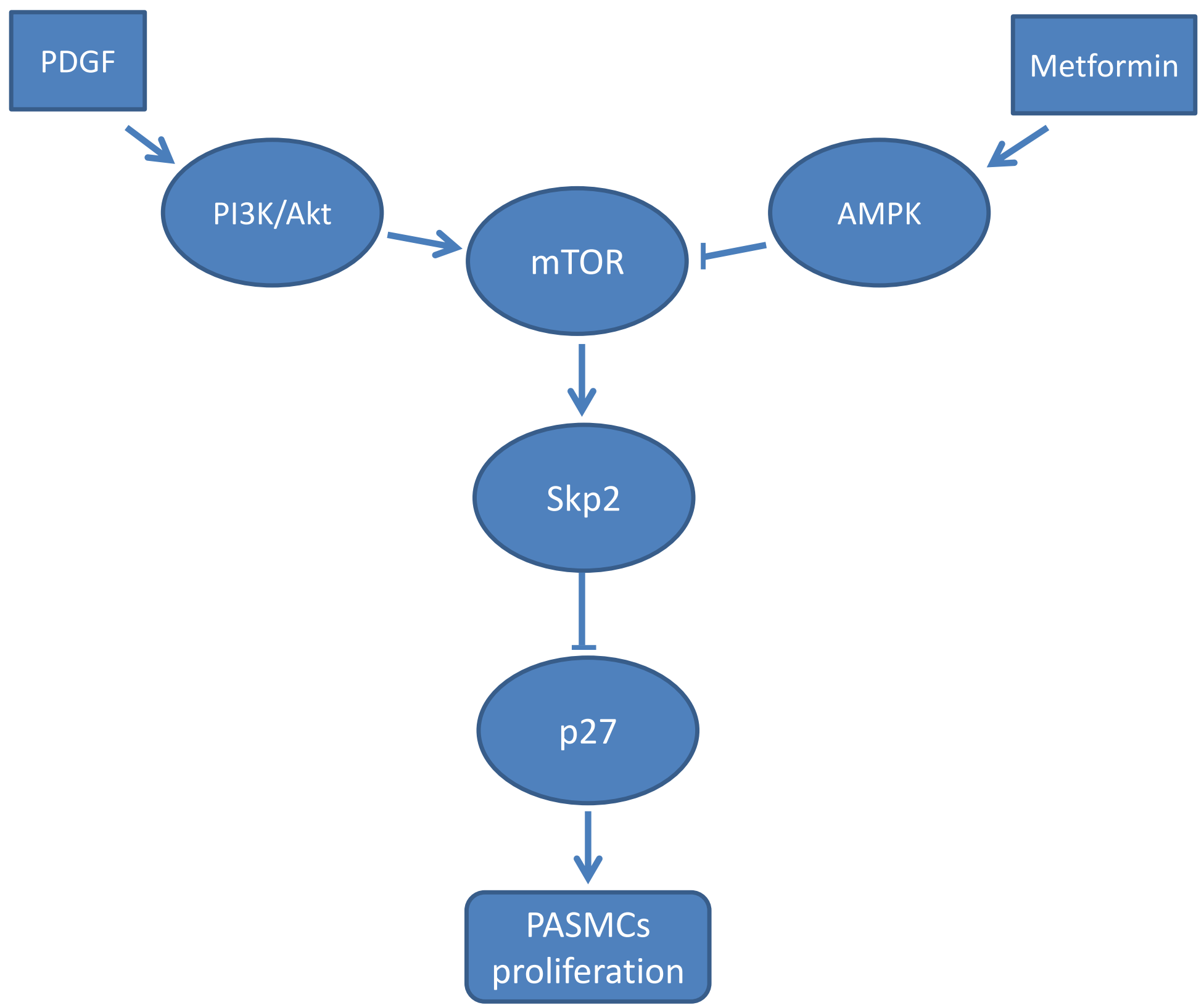

